Check for updates

Cite this: RSC Adv., 2019, 9, 26519

\title{
Enhanced surface activity of activated carbon by surfactants synergism
}

\begin{abstract}
Samuel Ntakirutimana, ${ }^{a}$ Wei $\operatorname{Tan}^{\mathrm{ab}}$ and Yang Wang (D) *ab
Activated carbon (AC) modification has been intensively studied in order to design carbon electrodes with enhanced electrochemical performance. Hexadecyltrimethylammonium bromide (HDTMA) and Tween 80 were employed for enhancing the surface activity of AC via synergism. The synergistic effects of the mixed surfactants on AC surface activity in the light of interface behaviors were studied. Both field emission scanning electron micrographs and FTIR spectra indicated a successful adsorption of loaded surfactants. AC gained a good wettability originated from the surfactants, especially in the binary mixture (T80HDTMA). The zeta potential results unveiled the positive charge density enhancement in the mixed surfactants system. Isoelectric point and point of zero charge implicate heterogeneous distribution of charges and the extent of surfactants treatment. Tween 80 displayed a significant size control dependence on AC particles. Electrochemical characterization revealed a higher specific capacitance and a decaying resistance of specific capacitance in AC-T80-HDTMA than AC-HDTMA at high concentration. In $5 \mathrm{~g} \mathrm{~L}^{-1}$ of NaCl, AC-T80-HDTMA (0.01:0.01 mM) exhibits the specific capacitance of $209.79 \mathrm{~F} \mathrm{~g}^{-1}$, at $0.8 \mathrm{~V}$ whereas AC-HDTMA $(0.01 \mathrm{mM})$ and $\mathrm{AC}$ exhibited $186.5 \mathrm{~F} \mathrm{~g}^{-1}, 178.9 \mathrm{~F} \mathrm{~g}$, respectively. Moreover, the stability testing reveals a strong attachment of HDTMA in AC-T80-HDTMA than AC-HDTMA with the loss of $0.32 \%$ and $1.32 \%$, respectively. The hypothetical synergistic mechanism of surfactants adsorption on the surface of AC was depicted as hydrophobic interaction and steric stabilization being the main keys for the synergy between cationic and nonionic surfactants. This study demonstrates the beneficial effects of mixed surfactants on AC electrode properties and discloses the impact on electrochemical performance.
\end{abstract}

Received 17th June 2019

Accepted 19th August 2019

DOI: $10.1039 / c 9 r a 04521 j$

rsc.li/rsc-advances charges on the surface is a prerequisite, especially in inverted CDI. This approach makes AC more effective, hydrophilic and acidic or basic due to the nature of charges.

Surfactants have been widely reported to induce different properties on the surface of AC, due to their aggregation behavior at the interface. Both cationic and anionic surfactants have been employed in the functionalization of AC. Choi and coworkers investigated cationic surfactant-modified AC for $\mathrm{Cr}(\mathrm{vI})$ removal from aqueous solution. ${ }^{3}$ AC modified with sodium dodecylsulphate and sodium diethyl dithiocarbamate were used for heavy metals removal from industrial phosphoric acid. ${ }^{4}$ Moreover, AC modified with sodium diethyl dithiocarbamate was studied for the removal of $\mathrm{Zn}, \mathrm{Cu}, \mathrm{Cr}$ whereas tetrabutyl ammonium iodide employed for the removal of $\mathrm{CN}^{-}$from wastewater. ${ }^{5}$ Furthermore, ACcetyltrimethylammonium chloride was applied for bromated removal $^{6}$ and cetylpyridinium chloride, cetyltrimethylammonium bromide, cetyltrimethylammonium chloride were also employed in AC modification. ${ }^{7}$ In addition, Shu et al. loaded cationic surfactants on AC for perchlorate adsorption. ${ }^{8}$ However, the mixed surfactants systems have been reported for more advantages (synergism) than a single surfactant system. ${ }^{9}$ Indeed, ionic-nonionic systems have been
${ }^{a}$ School of Chemical Engineering and Technology, Tianjin University, No. 135 Yaguan Road, Tianjin, 300350, PR China. E-mail: yangwang2017@tju.edu.cn; Tel: $+86-15822887531$

${ }^{b}$ Tianjin Key Laboratory of Membrane Science and Desalination Technology, Tianjin, 300072, PR China 
considered to offer more benefits over ionic-ionic or nonionic-nonionic systems. ${ }^{10}$

To date, the aggregation behavior of mixed surfactants in bulk solution and at interface has been investigated to enhance the performance and maintaining the stability. Many studies have been conducted on the mixed surfactants systems concerning their properties, adsorption and synergism. ${ }^{11}$ To the best of our knowledge, the studies about the synergistic effects of mixed surfactants on the surface activity of AC for electrochemical application have never been reported in the literature. Basically, a high accessibility of solution on the surface of adsorbents in adsorption process is very essential. However, AC is highly hydrophobic, and thus surfactants play the role to induce a high wettability for the sake of efficient performance in aqueous media. ${ }^{12}$ Furthermore, the dispersion medium has to wet the whole surface of the particles, including external and internal surfaces. ${ }^{13}$ Therefore, surfactants are always good candidate to enhance wettability and reduce surface tension. Noteworthy, ionic surfactants have been reported for a high $\mathrm{pH}$ sensitivity and poor dispersion, whereas nonionic surfactants are less sensitive to electrolyte $\mathrm{pH}$ and better dispersion which is attributed to their steric stabilization. ${ }^{14}$

Fic et al..$^{15}$ reported a profitable effects of nonionic surfactant (Triton X-100) on electrochemical properties of carbon electrode which is in accordance with the results reported by Ghasemi and Ahmadi. ${ }^{16}$ Moreover, Somasundaran and coworkers ${ }^{17}$ reported an increasing of cationic surfactant adsorption at the alumina-water interface in the presence of nonionic surfactant below saturation. Notably, due to the weakness of hydrophobic interaction, the detachment of surfactants from functionalized electrodes has been a challenge on electrochemical performance. Palko et al. reported adsorption capacity reduction of nitrate ions $\left(\mathrm{NO}_{3}{ }^{-}\right)$due to the loss of cetyltrimethylammonium ions from functionalized $\mathrm{AC}$ electrode surface..$^{18}$ Dejan and coworkers ${ }^{19}$ reported the synergistic effects of nonionic surfactants (Tween 80, Tween 20, Tween 60 and Triton X-100) with anionic surfactant on micellization. In essence, coulombic repulsion among ionic surfactants prompts them to occupy more surfaces which limit the amount to be adsorbed at interface. Consequently, a continuous detaching of ionic surfactants in adsorbed state results to the fading of cyclic stability specifically in electrochemical applications that depend on the surface chemical charges. In other words, the loss of surfactants attenuates the surface charge density associated with the decay of AC electrode performance.

Herein, a systematic study of the synergism between Tween 80 (T80) and hexadecyltrimethylammonium bromide (HDTMA) on the surface activity of AC for electrochemical application (capacitive deionization) was traced. Aggregation behaviors of a binary mixture (T80-HDTMA) and HDTMA were explored in the light of interfacial properties characterization. The benefits of Tween 80 as a co-surfactant on the applications of AC functionalized with cationic surfactants were established. This research provides a novel electrode with potential application for inverted CDI. Furthermore, it sheds light on the beneficial impact of surfactants mixture on the surface activity of AC than a single surfactant. The synergistic effects of mixed surfactants cannot only improve specific capacitance but also induce the stability of HDTMA in adsorbed state. Notably, nonionic surfactants are biodegradable and less toxic than cationic surfactants. The possible conformations illustrated in the last section of this work, indicate increased adsorption density and strong attachment of HDTMA in the presence of Tween 80 due to the fact that the steric stabilization, surfactant-surfactant lateral interaction and surfactant-AC hydrophobic interactions.

\section{Experimental}

\subsection{Materials}

Activated carbon (AC, YEC-8A) was obtained from Fuzhou Yihuan Carbon Ltd, China. Carbon black (VXC-72) was purchased from Cabot Corporation, U.S. cationic surfactant (HDTMA) nonionic surfactant (Tween 80 ) and $N$-methyl kelopyrrolidide (NMP) were purchased from Tianjin Yuanli Chemical Ltd, China. Polyvinylidene fluoride (PVDF, Kynar HSV 900) was obtained from Arkema, France. All analytical solutions were prepared with Milli-Q water.

\subsection{Activated carbon modification}

Stock solutions of cationic surfactant (HDTMA) and nonionic surfactant (Tween 80 ) were prepared at $10 \mathrm{mM}$ and $0.01 \mathrm{mM}$ respectively. $3 \mathrm{~g}$ of AC were added to $150 \mathrm{~mL}$ of HDTMA solutions $(0.01,0.7,5,10 \mathrm{mM})$ for adsorption. The binary mixture adsorption of HDTMA with Tween 80 was carried out sequentially and non-sequentially. For sequential adsorption $3 \mathrm{~g}$ of $\mathrm{AC}$ was added to $37.5 \mathrm{~mL}$ of Tween 80 solution $(0.01 \mathrm{mM})$ under sonication for $2 \mathrm{~h}$ and dried in oven for $24 \mathrm{~h}$ at $70{ }^{\circ} \mathrm{C}$. Then $150 \mathrm{~mL}$ of HDTMA solution was added and agitated at $170 \mathrm{rpm}$ on shaker for $48 \mathrm{~h}$. For non-sequential adsorption a molar fraction of $4: 1$ of HDTMA and Tween 80 for each concentration was added on $3 \mathrm{~g}$ of $\mathrm{AC}$ and then agitated on a shaker at $170 \mathrm{rpm}$ for $48 \mathrm{~h}$, similarly to the HDTMA system. The suspensions were filtrated, and the modified $\mathrm{AC}$ was dried in oven for $24 \mathrm{~h}$ at $70^{\circ} \mathrm{C}$. The amount of HDTMA loaded on AC was calculated from the difference between initial concentration and concentration in the filtrate. The virgin activated carbon was named AC, whereas modified activated carbon denoted AC-S. AC modified by HDTMA was named AC-HDTMA and AC modified by the binary mixture was named AC-T80-HDTMA.

\subsection{Characterization}

Both AC and AC-S were characterized by field emission scanning electron microscope (FE-SEM), Fourier transform infrared spectroscopy (FTIR). Wettability was evaluated by contact angle measurement. Zeta potential and isoelectric points were determined with Zetasizer. The point of zero charge was determined by drift method. The amount of cationic surfactant adsorbed and the stability on the adsorbent surface was estimated by two phase titration method. The particles size distribution was analyzed with Laser Particle Sizer. Specific capacitance and cyclic stability were determined by cyclic voltammetry (CV).

2.3.1 FE-SEM. Field emission scanning electron microscopy (S-4800, Hitachi, Japan) was used to analyze the surface 
physical morphology and qualitative characteristics of both AC and AC-S. Before FE-SEM analysis, the specimens were sprayed with gold.

2.3.2 FTIR. Fourier transform infrared spectroscopy (FTIR650 , Guangdong, China) analysis was performed in the range of $400-4000 \mathrm{~cm}^{-1}$. Transmission spectra of sample were recorded with applying $\mathrm{KBr}$ pellets technique ( $0.7 \%$ sample).

2.3.3 Contact angle. Wettability was evaluated by direct measurement of the contact angle with a conventional telescope-goniometer (CA-100C, Shanghai Zhenghong Instrument Co., Ltd, China). A slides-glass coated with both AC and AC-S samples were prepared. The contact angle formed by a drop of water resting on the surface to be tested was measured. A micrometer syringe was placed above the rotating specimen holder, and a drop of water expelled on the testing
2.3.6 Cationic surfactant titration and stability testing. Quantitative analysis of HDTMA adsorption onto AC was performed with two phase titration method. ${ }^{21}$ A portion of filtrate was taken from each suspension after adsorption. The analyte for binary mixture was taken from the sample prepared sequentially in order to avoid interference of Tween $80.10 \mathrm{~mL}$ of filtrate, $5 \mathrm{~mL}$ of phosphate buffer solution, 1 drop of tetrabromophenolphthalein ethyl ester indicator and $1.5 \mathrm{~mL}$ of 1,2dichloroethane were mixed in a $150 \mathrm{~mL}$ flask and Milli-Q water was added to a total volume of $20 \mathrm{~mL}$. The mixture was titrated with tetraphenylborate solution $\left(5 \times 10^{-2} \mathrm{mM}\right)$ under intermittent shaking to ensure equilibrium between the aqueous and organic phases. The cationic surfactant loaded onto AC was calculated based on the difference between initial concentration and the concentration in filtrate.

\section{$\left[\mathrm{CAS}^{+} \cdot \mathrm{In}^{-}\right]+\left[\right.$Titrant $\left.^{-}\right]+\mathrm{H}^{+}=[\mathrm{HIn}]+\left[\mathrm{CAS}^{+} \cdot\right.$ Titrant $\left.^{-}\right]$ \\ Blue \\ Yellow Colorless}

surface. The measurements were repeated several times for both advancing and receding contact angle. First the advancing contact angle was measured by expelling the droplet of water through a microsyringe, and then the receding contact angle was measured by using the microsyringe to reduce the droplet volume for angle hysteresis assessment. For each measurement a new part of the surface was used.

2.3.4 Zeta potential ( $\zeta$ ) and isoelectric point (IEP). In order to investigate the surface charge density, zeta potential $(\zeta)$ was measured under different electrolytes $\left(\mathrm{NaCl}\right.$ and $\left.\mathrm{Al}\left(\mathrm{NO}_{3}\right)_{3}\right)$ by a Zetasizer (Nano ZS, Malvern, United Kingdom). $50 \mathrm{mg}$ of AC, AC-HDTMA (0.7 mM) and AC-T80-HDTMA (0.01/0.7 mM) were taken into $250 \mathrm{~mL}$ of electrolyte solutions with the same ionic strength $(0.001 \mathrm{M})$. The mixtures were agitated on shaker at $170 \mathrm{rpm}$ for $6 \mathrm{~h}$, and then kept $15 \mathrm{~min}$ for sedimentation of big particles. Aliquots for measurements were taken under nitrogen at different $\mathrm{pH}$. The reading of each sample placed in electrophoresis cell was taken three times and their average was determined. The $\mathrm{pH}$ at which $\zeta$-potential is zero was considered as isoelectric point (IEP).

2.3.5 The point of zero charge $\left(\mathbf{p H}_{\mathrm{PZC}}\right)$. The point of zero charge $\left(\mathrm{pH}_{\mathrm{PZC}}\right)$ of AC, AC-HDTMA and AC-T80-HDTMA was determined following drift method. ${ }^{20}$ A solution of $0.01 \mathrm{M} \mathrm{NaCl}$ was made and bubbled with nitrogen gas to expel dissolved carbon dioxide. $50 \mathrm{~mL}$ of the solution was added to a series of beakers $(100 \mathrm{~mL})$, and $\mathrm{pH}$ was adjusted with $\mathrm{HCl}$ and $\mathrm{NaOH}$ in the range of 2 to $12.150 \mathrm{mg}$ of adsorbents was added in each beaker. The suspensions were agitated for $48 \mathrm{~h}$ at $250 \mathrm{rpm}$. Then the samples were filtrated and the final $\mathrm{pH}$ was measured. The $\mathrm{pH}$ difference $(\Delta \mathrm{pH})$ between final $\mathrm{pH}\left(\mathrm{pH}_{\mathrm{f}}\right)$ and initial $\mathrm{pH}$ $\left(\mathrm{pH}_{\mathrm{i}}\right)$ was plotted versus initial $\mathrm{pH}\left(\mathrm{pH}_{\mathrm{i}}\right)$, the point at which $\Delta \mathrm{pH}$ equal to zero was considered to be the $\mathrm{pH}_{\mathrm{PZC}}$.
The stability of cationic surfactant (HDTMA) on the surface of adsorbent was tested after CV (1000 cycles). Electrolytes were titrated by two phase titration method as described above. The amount of HDTMA detached from electrodes was calculated and converted into the loss (\%).

2.3.7 Particle size analysis. The particle size distribution of AC powder in different dispersant liquids was analyzed with a Laser Particle Size Analyzer (BT-9300ST, Dandong Bettersize, China). $0.05 \mathrm{~g}$ of AC was place in a series of beakers and $100 \mathrm{~mL}$ of dispersants liquid were added. All samples were prepared under sonication and the measurement for Tween 80 and HDTMA were taken at different concentration.

2.3.8 Electrochemical measurement. Electrochemical characterization was conducted on a three-electrode system through cyclic voltammetry (CV) with a potentiostat (CHI660E, Shanghai Chenhua, China). Standard calomel electrode was employed as reference electrode. The working and counter electrodes were prepared by mixing AC or AC-S with carbon black and PVDF in the ratio of $8: 1: 1$ respectively in NMP as solvent in order to get slurry of mixed solids. The slurry was coated on graphite-foil as current collectors and dried in oven at $70{ }^{\circ} \mathrm{C}$ for $24 \mathrm{~h}$. $\mathrm{CV}$ curves were recorded in the potential window range between -0.4 to $+0.4 \mathrm{~V}$ with a scan rate of $0.01 \mathrm{mV} \mathrm{s}^{-1}$. All fabricated electrodes were tested in $\mathrm{NaCl}\left(5 \mathrm{~g} \mathrm{~L}^{-1}\right)$ solution as electrolyte. Capacitance was calculated from the CV curves according to the following expression: ${ }^{22}$

$$
C=\frac{S}{2 v \Delta V}
$$

where $C$ is capacitance, $S$ is the area of CV curve, $v$ is the scan rate and $\Delta V$ is the voltage range. 


\section{Results and discussion}

\subsection{Morphology and interfacial characterization}

The FE-SEM images in the Fig. 1 displays different morphologies between AC and AC-S (AC-HDTMA and AC-T80-HDTMA). The image of pristine AC in Fig. 1a shows roughness and macropores on the surface, whereas AC-S looks smooth on its surface with a layer of surfactants. Furthermore, the AC-T80HDTMA sample in Fig. 1c shows a highly smooth surface and highly saturated with surfactants layer than AC-HDTMA sample in Fig. 1b. All these observations implicate effectiveness interaction between surfactants and AC surface via hydrophobic interaction.

The comparison of IR spectra of AC and AC-S in Fig. 2 shows the difference in both fingerprint and functional group regions. The wide band in the range of $3400-3500 \mathrm{~cm}^{-1}$ derive from the stretching mode of hydroxyl groups $-\mathrm{OH}\left(3450 \mathrm{~cm}^{-1}\right){ }^{23}$ The peaks in the range of $2700-3000 \mathrm{~cm}^{-1}$ can be attributed to the $\mathrm{C}-\mathrm{H}$ bending vibration. ${ }^{24}$ Two peaks at 2870 and $2930 \mathrm{~cm}^{-1}$, associated with the anti-symmetric and symmetric stretching vibration of $\mathrm{CH}_{2}$ from HDTMA chain. ${ }^{25}$ The band in the region $1600-1750 \mathrm{~cm}^{-1}$ can be assigned to $\mathrm{C}=\mathrm{O}$ group. ${ }^{26}$ The peaks in the range of $1250-1500 \mathrm{~cm}^{-1}$ can be assigned to $\mathrm{C}-\mathrm{H}$ bending of $\mathrm{CH}_{3}-\mathrm{R}\left(1389 \mathrm{~cm}^{-1}\right)$ and $\mathrm{CH}_{3}-\mathrm{N}\left(1430 \mathrm{~cm}^{-1}\right)$ stretching. ${ }^{25}$ The band at $1150 \mathrm{~cm}^{-1}$ is associated with ether $-\mathrm{C}-\mathrm{O}-$ symmetric and asymmetric stretching vibration of $-\mathrm{C}-\mathrm{O}-\mathrm{C}-$ ring in Tween $80 .^{27,28}$ The broad peaks in the range of $500-750 \mathrm{~cm}^{-1}$ correspond to $\mathrm{CH}_{2}$ rocking $\left(719 \mathrm{~cm}^{-1}\right)^{29}$ and $\mathrm{C}-\mathrm{O}$ stretching. ${ }^{24}$ The band at $488 \mathrm{~cm}^{-1}$ can be attributed to the anti-symmetric bending mode of the quaternary (alkyl) mode of the head of the methyl group $\left(\mathrm{CH}_{3}\right)_{3} \mathrm{~N}^{+}$in HDTMA. ${ }^{25,30}$

The contact angle measurement revealed the wetting behavior, the change of hydrophobic and hydrophilic intensity of both AC and AC-S. Both advancing and receding contact angles have shown similar trend on the surface wettability. The values of contact angles revealed the order of wettability, ACT80-HDTMA > AC-HDTMA > AC in Fig. 3. A high alteration of AC-T80-HDTMA wettability can be attributed to Tween 80 which has been reported for a high wetting power. Graca et al. ${ }^{31}$ reported the similar result for hydrophobic surface $\left(\theta>110^{\circ}\right)$ modification with Tween 80 , the values decrease to $70^{\circ}$ and $60^{\circ}$ at 0.01 and $0.1 \mathrm{mM}$, respectively. Furthermore, Kumar with

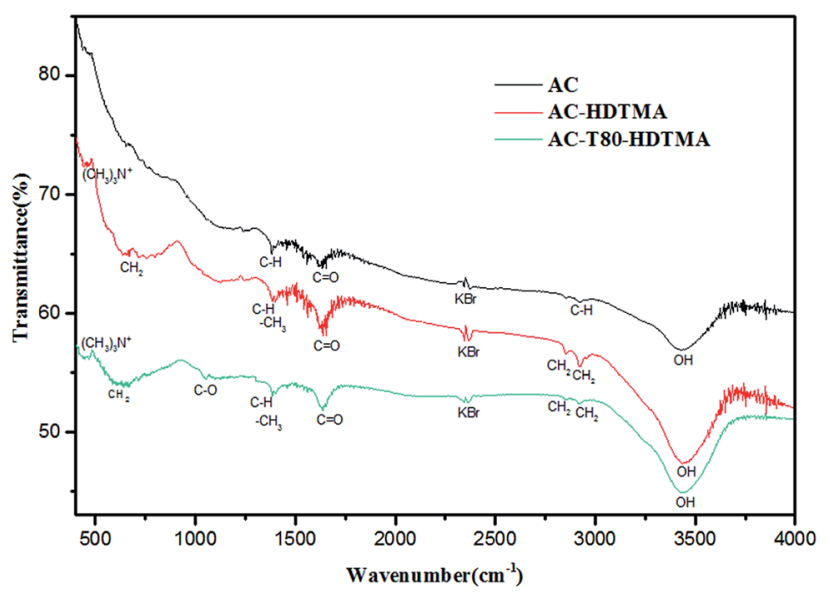

Fig. 2 FTIR transmission spectra of AC, AC-HDTMA and AC-T80HDTMA.

coworkers $^{32}$ reported a significant alteration of wettability on a carbonate surface modified with quaternary ammonium surfactants.

\subsection{Zeta potential and point of zero charge}

The $\zeta$-potential of AC and AC-S at different pH is shown in Fig. 4. Based on the variation of $\zeta$-potential, the surfactants rendered the surface of AC more positively charged. The shift of $\zeta$ potential to more positive region can be attributed to the high adsorption of HDTMA due to the effect of co-surfactant (Tween 80). This result is in accordance with the previous works ${ }^{9}$ that adsorption of cationic surfactant increases due to the presence of nonionic surfactant which reduces repulsion between cationic head groups via shielding. A similar result was reported by Curbelo et al. ${ }^{33}$ for enhanced adsorption of ionic surfactants in the presence of nonionic surfactants and vice versa. A significant increasing of $\zeta$-potential in AC-S can be attributed to the dissociation of HDTMA. Xu et al. ${ }^{34}$ reported a significant increasing of $\zeta$-potential at $\mathrm{pH}>4$ for granular AC coated with cationic surfactant (CTAC), due to the $\mathrm{CTA}^{+}$dissociation from CTAC. Similarly, HDTMA as a strong acid cationic surfactant can be positively ionized at $\mathrm{pH}$ close to neutral range. ${ }^{35}$
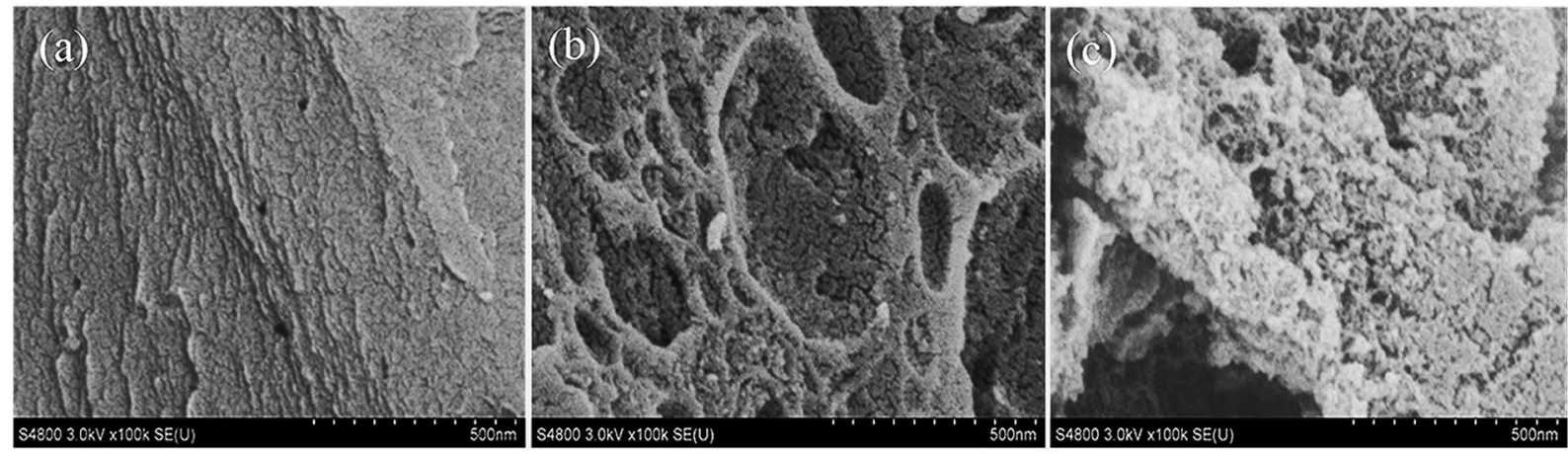

Fig. 1 Scanning electron microscopy images: (a) AC, (b) AC-HDTMA, (c) AC-T80-HDTMA 


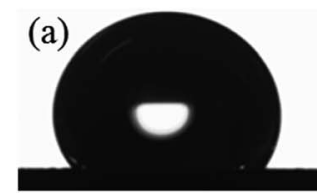

(b)

(c)

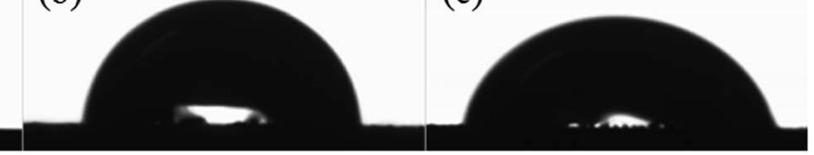

Fig. 3 Contact angle formed by water droplets on (a) AC: $\theta=124.63^{\circ} \pm 3.1$, (b) AC-HDTMA: $\theta=87.47^{\circ} \pm 2.7$, (c) AC-T80-HDTMA: $\theta=76.61^{\circ} \pm 2.9$.

The $\zeta$-potential dependence on pH of AC-T80-HDTMA was less significant than AC-HDTMA and the reason might be the less pH sensitivity of Tween 80 . Furthermore, the $\zeta$-potential of AC shown in Fig. 4a displayed a very negative zeta potential than AC-S (AC-HDTMA and AC-T80-HDTMA). AC-S has shown the shifting of zeta potential from negative to positive direction, indicating the increasing of surface positive charges originated from HDTMA. The shifting of zeta potential from negative toward positive direction in AC-T80-HDTMA is relatively higher than AC-HDTMA, which implicates more surface charges (more HDTMA adsorbed) in AC-T80-HDTMA than AC-HDTMA. Nevertheless, the net surface charge has remained in negative region, and this can be attributed to the usage of low concentration. At low HDTMA concentration, $\zeta$-potential of AC-S stays negative and becomes progressively positive with increasing of concentration. ${ }^{35}$ The relation between $\zeta$-potential, surface charge density and the valence of electrolyte ion could be stated in the following equations. ${ }^{36}$

$$
\sigma= \pm\left[\frac{k T \varepsilon}{2 \pi}\right]^{1 / 2}\left\{\sum_{i} n_{i}\left[\exp \left(-\frac{Z_{i} e \zeta}{k T}\right)-1\right]\right\}^{1 / 2}
$$

where $\sigma$ is surface charge density, $\varepsilon$ is dielectric constant, $e$ is electron charge, $k$ is Boltzmann constant and $T$ is the temperature. $n_{i}$ and $z_{i}$ are the ion number per unit liquid and the valence of ions, respectively.

$$
\frac{1}{k}=\frac{3}{Z C^{1 / 2}}
$$

where $1 / k$ is the diffuse layer thickness in Angstrom $(\AA), Z, C$ denote the valence and concentration, respectively.

The $\zeta$-potential can be indicator of the surface charge density. Low $\zeta$-potential indicates less surface charges, whereas high $\zeta$-potential indicates more charges on the surface of particles, which is in agreement with eqn (2). The increase of $\zeta$ potential after modification indicates augmentation of positive charges on the surface. HDTMA imparts the positive charge on AC surface, thus resulting in increased charges density. Fig. 4b shows the trend of $\zeta$-potential in $\mathrm{Al}\left(\mathrm{NO}_{3}\right)_{3}$ electrolyte where it became highly positive. The high positive $\zeta$-potential can be attributed to the effect of $\mathrm{Al}^{3+}$ ions on electrical double layer (EDL). The type of cations in electrolyte holds influence on the variation $\zeta$-potential. Monovalent cations yield more negative $\zeta$ potential than divalent cations whereas trivalent cations yield more positive $\zeta$-potential than divalent. ${ }^{37}$ According to eqn (3) multivalence cation $\left(\mathrm{Al}^{3+}\right)$ exerts a significant influence on $\zeta$ potential. Indeed, a solution with the same molarity and constant surface charge, a change of cation valence affects not only the $\zeta$-potential but also the thickness of the EDL. ${ }^{38}$ The $\zeta$ potential becomes positive due to the specific adsorption of $\mathrm{Al}^{3+}$ counter ions in the Inner Helmholtz Plane (IHP) of the stern layer. ${ }^{39}$ At low $\mathrm{pH}$ range of $\mathrm{AC}$ suspensions, $\mathrm{Al}^{3+}$ ions are in the non-hydroxyl form, while they can form hydroxyl complexes such as $\mathrm{Al}(\mathrm{OH})^{+}{ }_{2}, \mathrm{Al}(\mathrm{OH})^{2+}, \mathrm{Al}(\mathrm{OH})_{3}$ at low concentration or with increasing $\mathrm{pH}^{40}$ As a consequence, hydroxylated aluminum cations lead to a decreasing of $\zeta$-potential at low and high $\mathrm{pH}$ range, while the highest $\zeta$-potential observed in the range close to neutral $\mathrm{pH}$.

Isoelectric point (IEP) and point of zero charge $\left(\mathrm{pH}_{\mathrm{PZC}}\right)$ are important parameters in studies of chemical and electrochemical surface properties of adsorbents. According to electrochemical characterization of AC, IEP value has been suggested as the only representative of the external surface charges of carbon particles in the solution, whereas the $\mathrm{pH}_{\mathrm{PZC}}$ varies to the net total of internal and external surface charges of
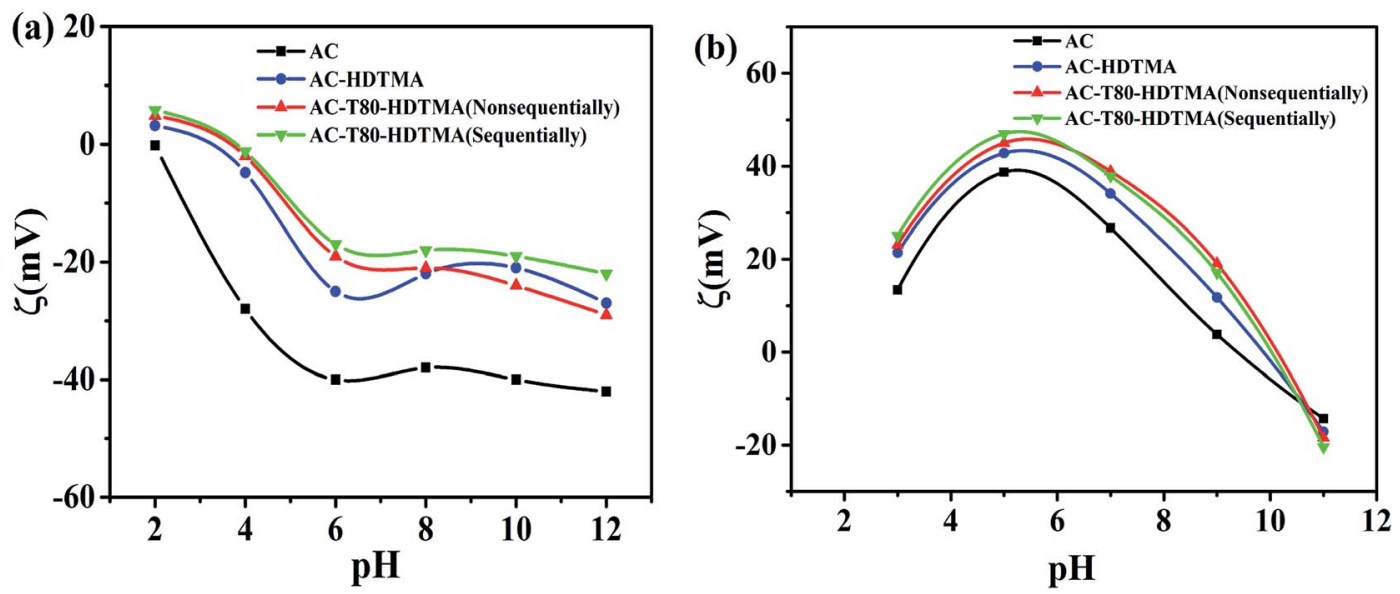

Fig. 4 The variation of $\zeta$-potential (a) in $0.001 \mathrm{M} \mathrm{NaCl}$, (b) in $0.001 \mathrm{M} \mathrm{Al}\left(\mathrm{NO}_{3}\right)_{3}$. 
the particles. ${ }^{41-43}$ The difference $\left(\mathrm{pH}_{\mathrm{PZC}}-\mathrm{IEP}\right)$ could be interpreted as a measure of the charge distribution on the surface. ${ }^{\mathbf{1 1}}$ The values greater than zero indicates that the particle is more negatively charged on external than internal, whereas the values close to zero indicate homogeneity distribution of the surface charges. ${ }^{41}$ IEP and $\mathrm{pH}_{\mathrm{PZC}}$ values of $\mathrm{AC}$ and AC-S in the Fig. 4a and 5 are shown in the Table $1 . \mathrm{pH}_{\mathrm{PZC}}$ increasing after modification indicates augmentation of positive charges density imparted by cationic surfactants. The differences of $\mathrm{pH}_{\mathrm{PZC}}$-IEP values of AC-S indicate that the treatment of original AC with surfactants has affected the surface at different extents. Moreover, the mixed surfactants render $\mathrm{AC}$ to the higher $\mathrm{pH}_{\mathrm{PZC}}$ than single surfactant, which make AC-T80-HDTMA relatively a better adsorbent than AC-HDTMA. Song et $a .^{43}$ reported a similar interpretation for surface modification of coconutbased AC, where modified $\mathrm{AC}$ with a high $\mathrm{pH}_{\mathrm{PZC}}$ exhibited the highest positive $\zeta$-potential. In addition, the increase of $\mathrm{pH}_{\mathrm{PZC}}$ for modified AC induces acidic behavior. The protons release becomes beneficial for cationic adsorption near neutral $\mathrm{pH}$. Contrarily a low $\mathrm{pH}_{\mathrm{PZC}}$ of virgin $\mathrm{AC}$ induces basic behavior near neutral $\mathrm{pH}$ thereby readily adsorb protons which compete with cations during adsorption.

\subsection{Cationic surfactant titration and stability test}

Cationic surfactant titration and stability testing data are summarized in Table 2. $2 \mathrm{wt} \%$ of AC, HDTMA (0.7 mM) and T80HDTMA prepared sequentially with Tween 80 (0.01 mM). Cationic titration shows a very high adsorption of HDTMA in both AC-HDTMA (91\%) and T80-HDTMA (98\%). Although the levels of adsorption are close to each other, further adsorption of HDTMA in the AC-T80-HDTMA formulation was observed beyond Critical Micelle Concentration (CMC, HDTMA-CMC = $0.9 \mathrm{mM}$ and Tween $80-\mathrm{CMC}=0.015 \mathrm{mM}$ ). This additional adsorption in the mixed system can be attributed to the effect of Tween 80, where steric stabilization bestows a free space prompted for adsorbing more HDTMA. Somasundaran et al. disclosed a continuous adsorption of surfactants mixture at the interface even above the CMC. ${ }^{9}$

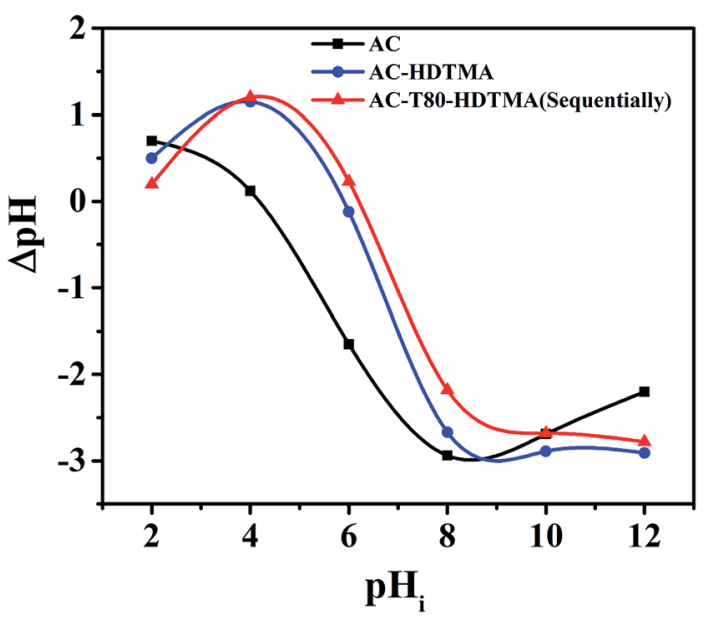

Fig. $5 \mathrm{pH}_{\mathrm{PZC}}$ of $\mathrm{AC}$ and $\mathrm{AC}-\mathrm{S}$ in $0.01 \mathrm{M}$ of $\mathrm{NaCl}$.
Table $1 \mathrm{pH}_{\mathrm{PZC}}$ and IEP of AC and AC-S

\begin{tabular}{llll}
\hline Type of adsorbent & $\mathrm{pH}_{\mathrm{pzc}}$ & $\mathrm{IEP}$ & $\mathrm{pH}_{\mathrm{pzc}}-\mathrm{IEP}$ \\
\hline AC & 4.2 & 1.98 & 2.22 \\
AC-HDTMA & 5.9 & 3.3 & 2.6 \\
AC-T80-HDTMA & 6.3 & 3.9 & 2.4 \\
\hline
\end{tabular}

The loss of cationic surfactant during cyclic voltammetry reveals the level of HDTMA stability on the solid surface. The low loss $(0.32 \%)$ in mixed surfactants indicates a high attachment of HDTMA on the surface of functionalized AC in the presence of Tween 80 . Contrarily, a relatively high loss $(1.32 \%)$ of HDTMA indicates a low stability on the surface of adsorbent. A better packing of ionic with nonionic surfactants mixture at interface, brings more advantages apart from steric stabilization and adsorption density. Both HDTMA and Tween 80 have a very long hydrophobic chain tail (very low inductive effect) with 16C and 18C, respectively. Therefore chain-chain lateral interaction and chain tail-activated carbon interaction induce a strong hydrophobic interaction.

The lateral chain-chain interaction between surfactants on interface, results into surfactants clusters formation at the interface. ${ }^{44}$ Qun et al. ${ }^{45}$ suggested the chain-chain interaction between surfactants in adsorbed state as the main cause for synergism. Electrochemical characterization, specifically the cycling stability has been reported in many literatures for nonionic surfactants. ${ }^{15,16,45}$ A high stability in AC-T80-HDTMA formulation can be also attributed to the favorable packing of surfactants in adsorbed films, due to the dissimilarity and large difference in size, between the head groups of HDTMA and Tween $80 .{ }^{47}$ Furthermore, the presence of two $\mathrm{sp}^{2}$ hybridized Catoms in the chain tail of Tween 80 can involve in the synergism. This weak dipole can polarize hydrocarbon chains of cosurfactants, generating a weak induced dipole. ${ }^{19}$ This electrostatic attractive interaction between induced dipole and dipole contribute to the high stability and synergy in general.

\subsection{Particle size distribution}

The comparative effects of dispersant liquids (Tween 80, HDTMA and Water) on AC particles size are shown in Fig. 6. Tween 80 solution provides a highly dispersed suspension with a remarkable size decrease of the particles. In Fig. 6a, the modes of the particle size distribution were found in the regions 6.7-11 $\mu \mathrm{m}, 11.2-18.25 \mu \mathrm{m}$ and $12.8-21.48 \mu \mathrm{m}$ for $0.1,0.01$ and $1 \mathrm{mM}$ Tween 80, respectively. Insufficient or too much concentration might impede solid dispersion or increase particles size via agglomeration; hence the proper concentration is critical. Guo et $a .^{48}$ reported the particle size of ultra-fine powders in aqueous media decreases with the increase of SDS concentration, then increases with further concentration increasing. The size increasing was attributed to the binding of surfactant molecules on the fully occupied particle surface through hydrophobic interaction beyond equilibrium adsorption capacity, which causes agglomeration of the particles. In Fig. 6b, the mode was found in the regions 33.8-42.15, 42.15- 
Table 2 Analytical data for HDTMA titration after AC modification and after CV

\begin{tabular}{lll}
\hline & AC-T80-HDTMA & AC-HDTMA \\
\hline Initial concentration $\left(C_{\mathrm{i}}\right)$ & $0.7 \mathrm{mM}$ & $0.7 \mathrm{mM}$ \\
Number of moles in solutions & $0.105 \mathrm{mmol}$ & $105 \mathrm{mmol}$ \\
Concentration of filtrate after adsorption & $1.95 \times 10^{-3} \mathrm{mM}$ & $3.07 \times 10^{-3} \mathrm{mM}$ \\
Number of moles adsorbed & $0.103 \mathrm{mmol}$ & $0.095 \mathrm{mmol}$ \\
Adsorption (\%) & $98 \%$ & $91 \%$ \\
Number of moles in electrode before CV & $1.55 \times 10^{-3} \mathrm{mmol}$ & $1.06 \times 10^{-3} \mathrm{mmol}$ \\
Concentration in electrolyte after CV & $2.5 \times 10^{-5} \mathrm{mM}$ & $7 \times 10^{-5} \mathrm{mM}$ \\
Number of moles in electrolyte after CV & $5 \times 10^{-6} \mathrm{mmol}$ & $1.4 \times 10^{-5} \mathrm{mmol}$ \\
Loss $(\%)$ & $0.32 \%$ & $1.32 \%$
\end{tabular}

67.4 and 47.3-75 $\mu \mathrm{m}$ at 10, 1 and $0.1 \mathrm{mM}$ HDTMA, respectively, which are larger than the ones from Fig. 6a. The comparative effects of dispersant liquids (Tween 80, HDTMA and water) are shown in Fig. 6c, where water and HDTMA displayed the mode with big particle $(34-78.5 \mu \mathrm{m})$ while Tween 80 displayed small particles $(11-21 \mu \mathrm{m})$. The size distribution under sonication with time was also investigated in Fig. 6d. 90-120 min was found as the optimal time for dispersion process. Small particles are highly required for effective adsorption. However, AC powder particles and clumps always tend to stuck together to form agglomerates and aggregates. A well dispersed suspension is critical in order to get individual particles in stable state. One of the goals of using Tween 80 is to keep particles apart and this barrier to agglomeration makes adsorption of HDTMA more effective. Obviously, Tween 80 does not only disperse particles but also downsizes agglomerates by inducing steric barrier which expands the surface for adsorption.

Tween 80 is well known for a high Hydrophilic-Lipophilic Balance (HLB) and has been widely used as dispersant and stabilizing agent. Suchomel et al. ${ }^{49}$ applied Tween 80 for simple (a)

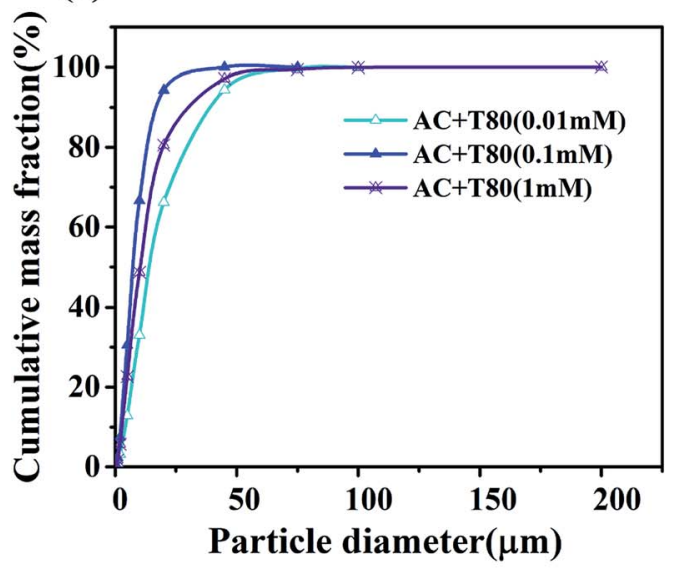

(c)

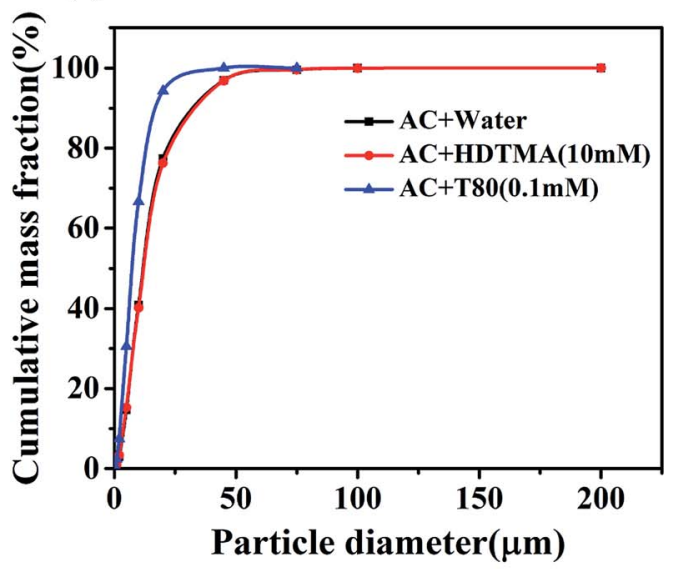

(b)

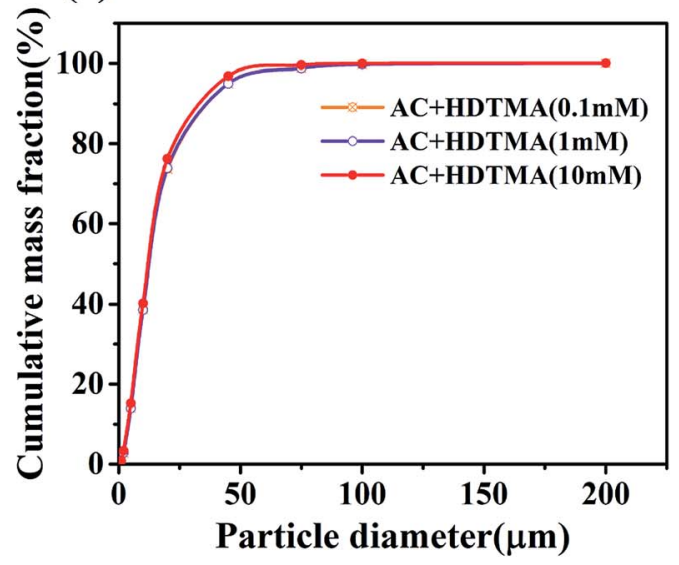

(d)

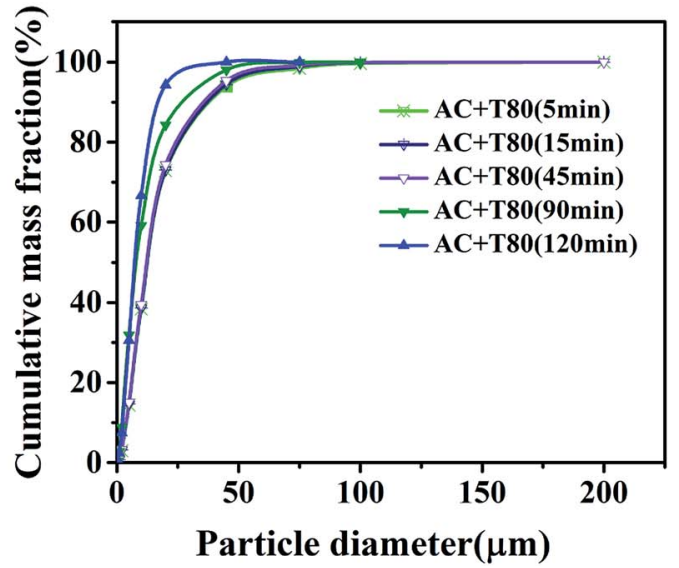

Fig. 6 Particle size distribution of $\mathrm{AC}$ (a) as function of Tween 80 concentration, (b) as function of HDTMA concentration, (c) as function of Water, HDTMA and Tween 80 , (d) as function of sonication time (0.1 mM of Tween 80$)$. 
size-controlled synthesis of nanoparticles. This class of surface acting agents acts as stabilizing agents by inducing steric stabilization. Steric stabilization is the presence of physical barriers on particles that prevent them from coming close enough to allow the van der Waals attractive forces among particles to dominate. ${ }^{50}$ The conformation of surfactants at the moment when adsorbed on the surface is controlled by both solution-surfactants and particles-surfactants interaction. The increasing of closeness between particles in order to minimize van der Waals attraction forces is the key for steric stabilization. ${ }^{51,52}$ The presence of stabilizing agents reduces attraction at the closest distance among particles and hence the prevention of agglomeration makes the manipulation of particles easily under steric stabilization dominance. Dispersion of solids in the liquid can be stabilized by steric barriers in the presence or absence of electrical barriers. Tadros ${ }^{51}$ reported two effect of steric stabilization: (1) mixing effect and (2) entropic effect. These forces supply the repulsive barrier that prevents particle agglomeration in such sterically stabilized systems. Although ionic surfactants act as stabilizing agents via electrostatic stabilization, steric stabilization has more advantages over electrostatic stabilization. Steric stabilization has low sensitivity on high concentration of electrolytes, low viscosities for high solids dispersions and is equally effective in aqueous and nonaqueous media. ${ }^{53}$

\subsection{Electrochemical characterization}

Fig. 7 shows the specific capacitance $\left(\mathrm{F} \mathrm{g}^{-1}\right)$ of $\mathrm{AC}$ and $\mathrm{AC}-\mathrm{S}$ at different concentrations of surfactants. At low concentration (less than CMC), electrodes display improved specific capacitance. This enhancement can be attributed to the stable porosity and good wettability that can induce a high usable surface area and lower internal resistance of carbon electrodes, which is in accord with the work of Fang et al. ${ }^{54}$ Similarly, Tamborini et al. ${ }^{55}$ assigned surfactants as porosity stabilizer in porous carbons. Furthermore, Zhang et $a .^{46}$ disclosed the impact of optimal concentration of CTAB on the surface and pore size of carbon electrode, associated with the high capacitance, cyclic stability and low resistance. Fig. 7a shows the variation in specific capacitance of AC modified with various concentrations at a voltage of $0.8 \mathrm{~V}$. The specific capacitance of AC was178.9 $\mathrm{F} \mathrm{g}^{-1}$, while AC-HDTMA, AC-T80-HDTMA displayed 186.5 and $209.79 \mathrm{~F} \mathrm{~g}^{-1}$ respectively (at $0.01 \mathrm{mM}$ ).

Noteworthy, T80-HDTMA displays more wetting power than HDTMA. The decreasing of the surface tension on interface allows a better penetration of electrolyte into the pores. Furthermore, the effect of Tween 80 on size distribution of AC particles contribute to the specific capacitance improvement. Basically, nonionic surfactants hold a remarkable detachment ability on powdered particles from parent agglomerates. Consequently, the formation of individual particles or smaller agglomerates generate a high surface with more adsorption sites. In Fig. 7b, AC-T80-HDTMA displayed better cycling stability than AC-HDTMA. The mixed surfactants can be accredited to maintain porosity of AC than a single cationic surfactant. Ghasemi and Ahmadi ${ }^{\mathbf{1 6}}$ investigated the effect of nonionic and ionic surfactant on capacitive behavior on nanocomposites. Notably, nonionic surfactant induced the highest capacitance improvement and excellent cycling stability. Also, nonionic surfactant have been reported for their beneficial effects not only on charge propagation but also on electrode voltage window. In addition, Akinori et al. delineated improvement of capacitance with addition of surfactants to an aqueous electrolyte. ${ }^{56}$

In a sense, a radical improvement of EDL specific capacitance was ascribed to the effective access of electrolyte the inner surface of electrode micropores. However a progressive decreasing of specific capacitance at high concentration (>CMC) was observed. The capacitance decaying can be attributed to the reduced specific surface area and pore volume covered by micelles, where the micelles formation makes the access of electrolyte to the pore more difficult. Moreover, the excess surfactants molecules in the pores causes retardation of ions transport and decreasing of usable surface. Despite of the decreasing of specific capacitance at high concentration, the T80-HDTMA has shown a resistance on diminishing of capacitance compared with HDTMA due to the reasons mentioned previously.
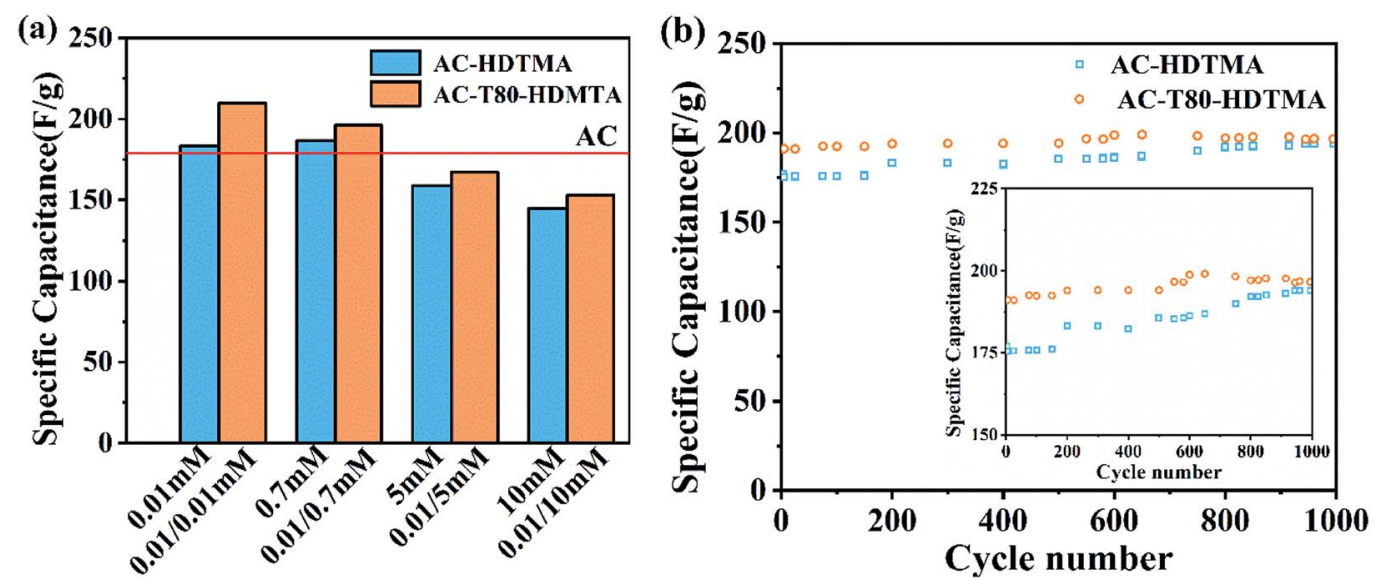

Fig. 7 The influence of surfactants on (a) specific capacitance, (b) cyclic stability testing. 


\section{Mechanism of Tween 80 and HDTMA synergism}

The synergism between ionic and nonionic surfactants can be explained in the light of their thermodynamic alternative arrangement in solution or at interface. ${ }^{57}$ Unlike nonionic surfactants, ionic surfactants solvation in water is always limited by coulombic repulsion force that rises from head groups with similar charges. A similar situation occurs during adsorption on interface, where coulombic repulsion dominates the surfactants arrangement mechanism which causes molecules to stay away from each other. Nonionic surfactants mixed with ionic surfactants have been widely reported to avert coulombic repulsion via steric hindrance, which brings ionic surfactant molecules close to each other. Adsorption density of cationic surfactant increases, due to the presence of nonionic surfactant which reduces the repulsion between cationic head groups via shielding was reported as the main cause. A high surface activity of nonionic surfactants and hydrophobic interaction with ionic surfactants are considered to be the main factors for entropic effect in the mixture. ${ }^{44}$

Basically, the synergism between ionic and nonionic surfactants can lead to increased adsorption of ionic surfactants. ${ }^{33}$ Indeed, adsorption tests have proved reinforcement between ionic and nonionic surfactants in the mixed system. Moreover, they may also force each other to adsorb at interface, even when an individual adsorption could not occur. ${ }^{33}$ Steric effect of nonionic surfactant can be regarded as one of the main keys for the stability and enhanced adsorption density of ionic surfactants at interface. Naturally, surfactants are amphiphilic molecules with both polar region (hydrophilic head) and nonpolar region (hydrophobic tail). Hence, their aggregation behaviors in solution result to the different conformations. Hydrophilic group is favorable to associate with water molecules whereas hydrophobic tail is thermodynamically unfavorable to associate with water molecules. Rulison ${ }^{57}$ reported a thermodynamic conflict which perpetually rises in the water with regard to surfactants, where he described the interaction of water molecules with hydrophilic group, as the most favorable solution for that conflict.

The orientation of surfactants at interface originates from heterogeneity of their molecules. Since AC is highly hydrophobic, the hydrophobic parts of surfactant molecules, under the control of entropic and enthalpic favorability are forced to associate with AC surface. Knowing that, the mechanisms of HDTMA and Tween 80 arrangement on the surface of AC particles in suspension have been proposed in Fig. 8 that portrays adsorption of surfactants on AC particles. Graca et al. ${ }^{31}$ disclosed the mechanism of aggregational behavior of Tween surfactants at interface, wherein alkyl chains adsorb at the hydrophobic surface whereas the ethylene oxide head groups oriented into the water solution. Fig. 8a shows the hypothetical arrangement of HDTMA under coulombic repulsion control. HDTMA molecules tend to occupy the sites far from each other on the surface of AC particles in order to minimize coulombic repulsion force among their head groups with the same charges. Fig. 8b displays a distinct arrangement of HDTMA with Tween 80 in a binary system. Tween 80 induces a steric hindrance that quenches coulombic repulsion among head groups of cationic surfactant molecules. HDTMA molecules come close to each other thus a free space is prompted to adsorb additional HDTMA molecules.

The aggregation of surfactants on the solids surface has the similar analogy to aggregation in the bulk solution. Gangula et al. reported admicelles and hemimicelles as new investigated phenomena of surfactants adsorption on the solid surface. ${ }^{58}$ The formation of the bilayer, which is analogue to the micelles in bulk solution, on the solid surface during adsorption was coined admicelle and a monolayer formation was, coined hemimicelle. It is well known that micelles formation occurs at CMC. On the contrary, admicelle occurs when surfactant concentration is less than CMC. ${ }^{58}$ The formation of admicelles and hemimicelles on the surface, depends on different parameters, including surfactants concentration, electrolyte type and concentration, adsorbents $\mathrm{pH}$ and surface chemistry. ${ }^{13,59,60}$

The proposed mode of adsorption in Fig. 8c, depicts the interactions of AC sites with a mixed solution of Tween 80 and HDTMA at concentration close to CMC. In Fig. 8c hydrophobic chains of both cationic and nonionic surfactants interact with AC via hydrophobic interaction, and chain-chain lateral interaction among surfactants in adsorbed state. At high concentration, the surface becomes saturated and hence the occurrence of admicelles formation takes place. The excess cationic surfactants start to penetrate the monolayer of surfactants in adsorbed state. In fact, $\mathrm{AC}$ has dual nature for adsorbing both non polar and polar compounds, thus the mechanism of adsorption leads to different orientation of surfactants on the surface. Both hydrophobic tail and hydrophilic head might interact with AC, either by hydrophobic interaction (dominant), or dispersion forces. In the Fig. 8d, both HDTMA and Tween 80 molecules may take different orientations depending on the AC sites they interact with. The formation of the second layer might be originated from hydrophobic interaction between surfactants with opposite orientation, or the penetration into the monolayer to form a mixed conformation.

AC modified with surfactants hold potential application in electrosorption process, where surface charges and wettability play a significant role. AC electrodes functionalized with ionic surfactants have recently attracted considerable attention in capacitive deionization technology (CDI), specifically inverted capacitive deionization system. Fig. 9 shows adsorption of anions on AC modified with a binary mixture of Tween 80 and HDTMA. The presence of Tween 80 shows enhanced adsorption density of HDTMA, in the perfect packing (high stability) which are both worthy in electrosorption process. Indeed, enhanced adsorption density of HDTMA induces a high adsorption capacity of anion pollutants. Moreover, improved packing imparts the stability of surfactants on the surface. These peculiar effects are among the ultimate goals of mixed surfactants system application for the sake of enhanced surface activity of AC, which could never, occurs for a single surfactant system. 
(a)
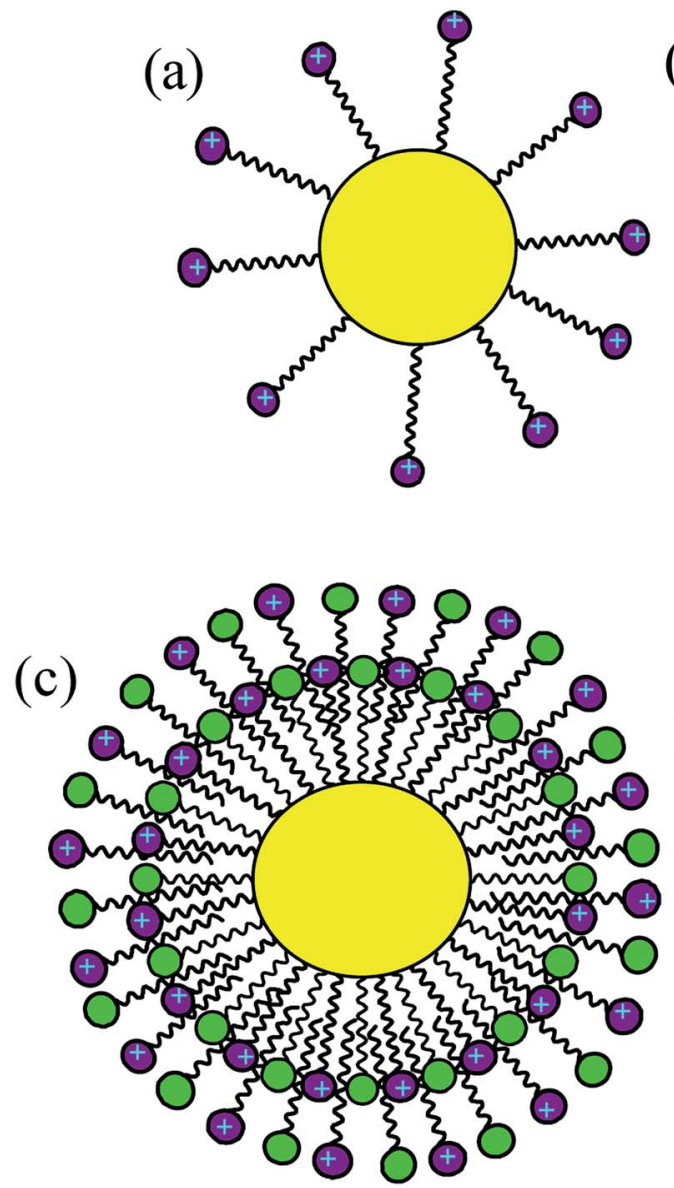

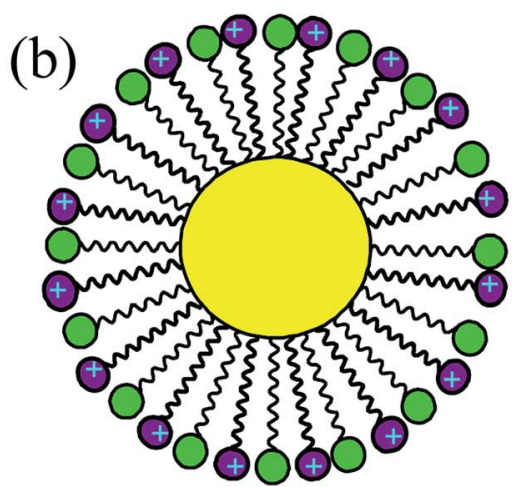

(d)

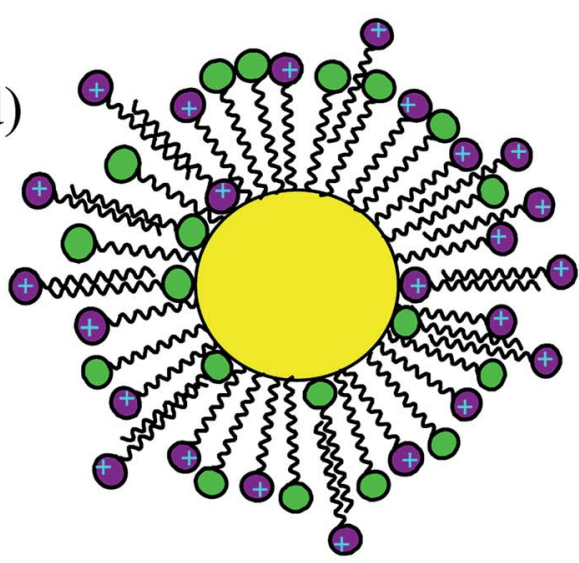

Fig. 8 The arrangement of (a) HDTMA, (b) T80-HDTMA on the surface of AC particle in the form of monolayer (hemimicelle) at low concentration, (c) penetrated, (d) mixed bilayer (admicelle) at high concentration.

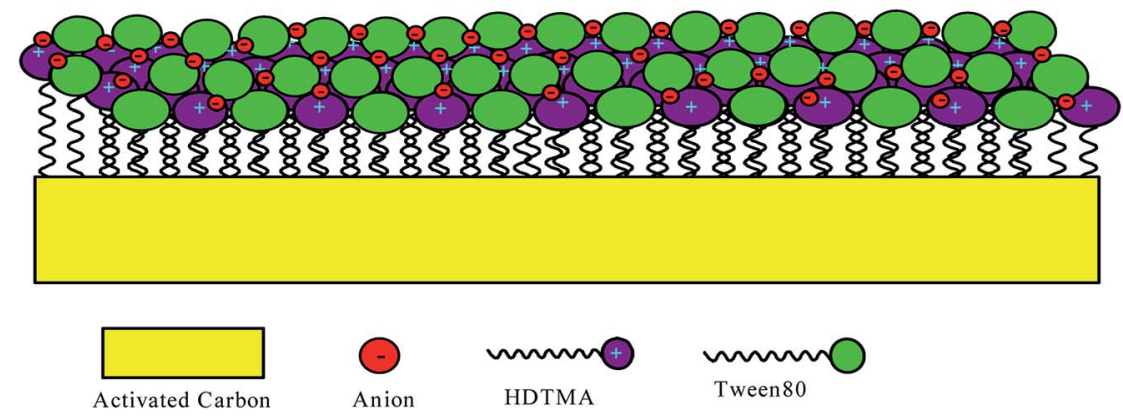

Fig. 9 Adsorption of anions on functionalized AC electrode.

\section{Conclusion}

A well-designed surfactants mixture can enhance physical/ chemical and electrochemical properties of AC electrode to the level a single surfactant cannot reach individually. The Tween 80 and HDTMA mixed system revealed tremendous benefits over HDTMA system in this study. AC gained a good wettability due to the effect of Tween 80 which is very crucial in adsorption process. Cationic titration in the AC-T80-HDTMA formulation treated sequentially, revealed enhanced adsorption density of HDTMA. Furthermore, zeta potential values unveiled more positive charge density for AC treated with mixed surfactants than single surfactant. Isoelectric point (IEP) and the point of zero charge $\left(\mathrm{pH}_{\mathrm{PZC}}\right)$ revealed the extent of modification and charge distribution. A significant size dependence activity of Tween 80 on powdered activated carbon was observed. Electrochemical characterization revealed a better enhancement of specific capacitance in AC-T80-HDTMA than AC-HDTMA even at the concentration higher than CMC. The stability testing revealed a high attachment of HDTMA on the surface of functionalized AC particles in the presence of Tween 80 , with a stable cycling. Moreover, the hypothetical mechanism 
of surfactants on the surface of AC particles was depicted. The formulation of nonionic surfactant mixed with ionic surfactants induces better interfacial behaviors than individual ionic surfactant. In a sense, a mixture of HDTMA with Tween 80 holds peculiar effects on enhancement of AC surface activity. However, inadequate amount of Tween 80 could impede the synergism; hence the optimal molar fraction with ionic surfactants is highly recommended. For further investigation, we would like to shed the light on the effects of these surfactants on Electrical Double Layer (EDL) thickness and adsorption capacity of AC-S. The impact of dissimilarity and difference in size between the head groups of HDTMA and Tween 80 on ions selectivity is worthy to be further explored.

\section{Conflicts of interest}

There are no conflicts to declare.

\section{Acknowledgements}

The authors would like to express gratitude to the National Natural Science Foundation of China (No. 21808160) for the financial support.

\section{References}

1 A. Bhatnagar, W. Hogland, M. Marques and M. Sillanpää, An overview of the modification methods of activated carbon for its water treatment applications, Chem. Eng. J., 2013, 219, 499-511.

2 T. Gupta, Carbon: the black, the gray and the transparent, Springer, 2017.

3 H.-D. Choi, W.-S. Jung, J.-M. Cho, B.-G. Ryu, J.-S. Yang and K. Baek, Adsorption of Cr (VI) onto cationic surfactantmodified activated carbon, J. Hazard. Mater., 2009, 166, 642-646.

4 L. Monser, M. B. Amor and M. Ksibi, Purification of wet phosphoric acid using modified activated carbon, Chem. Eng. Process., 1999, 38, 267-271.

5 L. Monser and N. Adhoum, Modified activated carbon for the removal of copper, zinc, chromium and cyanide from wastewater, Sep. Purif. Technol., 2002, 26, 137-146.

6 W.-f. Chen, Z.-Y. Zhang, Q. Li and H.-Y. Wang, Adsorption of bromate and competition from oxyanions on cationic surfactant-modified granular activated carbon (GAC), Chem. Eng. J., 2012, 203, 319-325.

7 W. Farooq, H.-J. Hong, E. J. Kim and J.-W. Yang, Removal of Bromate $\left(\mathrm{BrO}_{3}{ }^{-}\right)$from Water using Cationic SurfactantModified Powdered Activated Carbon (SM-PAC), Sep. Sci. Technol., 2012, 47, 1906-1912.

8 S.-Y. Lin, W.-f. Chen, M.-T. Cheng and Q. Li, Investigation of factors that affect cationic surfactant loading on activated carbon and perchlorate adsorption, Colloids Surf., A, 2013, 434, 236-242.

9 P. Somasundaran and L. Huang, Adsorption behavior of surfactant mixtures at solid-liquid interface, Pol. J. Chem., 1997, 71, 568-582.
10 P. Holland, in Mixed Surfactant Systems, ed. P. M. Holland and D. N. Rubingh, ACS Symposium Series, 1992, p. 31.

11 M. Rosen, J. Kunjappu, Molecular interactions and synergism in mixtures of two surfactants, Surfactants and Interfacial Phenomena, 2012, vol. 4.

12 D. Kohli, R. Singh, M. Singh, A. Singh, R. Khardekar, P. Ram Sankar, P. Tiwari and P. Gupta, Study of carbon aerogelactivated carbon composite electrodes for capacitive deionization application, Desalin. Water Treat., 2012, 49, 130-135.

13 B. Palla and D. Shah, Stabilization of high ionic strength slurries using surfactant mixtures: molecular factors that determine optimal stability, J. Colloid Interface Sci., 2002, 256, 143-152.

14 P. Somasundaran and D. Fuerstenau, Mechanisms of alkyl sulfonate adsorption at the alumina-water interface, $J$. Phys. Chem., 1966, 70, 90-96.

15 K. Fic, G. Lota and E. Frackowiak, Effect of surfactants on capacitance properties of carbon electrodes, Electrochim. Acta, 2012, 60, 206-212.

$16 \mathrm{~S}$. Ghasemi and F. Ahmadi, Effect of surfactant on the electrochemical performance of graphene/iron oxide electrode for supercapacitor, J. Power Sources, 2015, 289, 129-137.

17 L. Huang, C. Maltesh and P. Somasundaran, Adsorption behavior of cationic and nonionic surfactant mixtures at the alumina-water interface, J. Colloid Interface Sci., 1996, 177, 222-228.

18 J. W. Palko, D. I. Oyarzun, B. Ha, M. Stadermann and J. G. Santiago, Nitrate removal from water using electrostatic regeneration of functionalized adsorbent, Chem. Eng. J., 2018, 334, 1289-1296.

19 D. M. Cirin, M. M. Posa, V. S. Krstonosic and M. L. Milanovic, Conductometric study of sodium dodecyl sulfate-nonionic surfactant (Triton X-100, Tween 20, Tween 60, Tween 80 or Tween 85) mixed micelles in aqueous solution/ Konduktometrijsko ispitivanje mesovitih micela nadodecilsulfata i nejonskog surfaktanta (Triton X-100, Tween 20, Tween 60, Tween 80 ili Tween 85) u vodenim rastvorima, Hem. Ind., 2012, 66, 21-29.

20 I. D. Mall, V. C. Srivastava, G. V. A. Kumar and I. M. Mishra, Characterization and utilization of mesoporous fertilizer plant waste carbon for adsorptive removal of dyes from aqueous solution, Colloids Surf., A, 2006, 278, 175-187.

$21 \mathrm{M}$. Tsubouchi, H. Mitsushio and N. Yamasaki, Determination of cationic surfactants by two-phase titration, Anal. Chem., 2002, 53, 1957-1959.

22 Y. Wang, M. I. Tejedor-Tejedor, W. Tan and M. A. Anderson, Importance of Protons and Specifically Adsorbing Ions on Changing Capacitance, Space Charge Potential Inside the Solid, and the Interfacial Potential at the TiO2 Aqueous Solution Interface, Electrochim. Acta, 2016, 219, 577-587.

23 T. Yang and A. C. Lua, Characteristics of activated carbons prepared from pistachio-nut shells by physical activation, J. Colloid Interface Sci., 2003, 267, 408-417.

24 Z. Lendzion-Bieluń, Ł. Czekajło, D. Sibera, D. Moszyński, J. Sreńscek-Nazzal, A. W. Morawski, R. J. Wrobel, 
B. Michalkiewicz, W. Arabczyk and U. Narkiewicz, Surface characteristics of $\mathrm{KOH}$-treated commercial carbons applied for CO2 adsorption, Adsorpt. Sci. Technol., 2017, 36, 478-492.

25 U. Aroke and U. El-Nafaty, XRF, XRD and FTIR properties and characterization of HDTMA-Br surface modified organo-kaolinite clay, International Journal of Emerging Technology and Advanced Engineering, 2014, 4, 817-825.

26 D. Cuhadaroglu and O. A. Uygun, Production and characterization of activated carbon from a bituminous coal by chemical activation, Afr. J. Biotechnol., 2008, 7, 20.

27 R. Lapuente, F. Cases, P. Garces, E. Morallon and J. Vázquez, A voltammetric and FTIR-ATR study of the electropolymerization of phenol on platinum electrodes in carbonate medium: Influence of sulfide, J. Electroanal. Chem., 1998, 451, 163-171.

28 F. Branzoi and V. Branzoi, Investigation of Some Nonionic Surfactants as Corrosion Inhibitors for Carbon Steel in Sulfuric Acid Medium, Int. J. Electrochem. Sci., 2017, 12, 7638-7658.

29 K. R. Rodriguez, H. Tian, J. M. Heer, S. Teeters-Kennedy and J. V. Coe, Interaction of an infrared surface plasmon with an excited molecular vibration, J. Chem. Phys., 2007, 126, 151101.

30 H.-C. M. J. Kaolinite, Properties and Characterization of HDTMA-Cl Modified Jordanian Kaolinite and Its Use in Removal of Aniline from Aqueous Solution, Chemistry, 2014, 3, 10.

31 M. Graca, J. H. Bongaerts, J. R. Stokes and S. Granick, Friction and adsorption of aqueous polyoxyethylene (Tween) surfactants at hydrophobic surfaces, J. Colloid Interface Sci., 2007, 315, 662-670.

32 S. Kumar, P. Panigrahi, R. K. Saw and A. Mandal, Interfacial Interaction of Cationic Surfactants and Its Effect on Wettability Alteration of Oil-Wet Carbonate Rock, Energy Fuels, 2016, 30, 2846-2857.

33 F. D. S. Curbelo, A. I. C. Garnica, T. N. Castro Dantas and E. L. Barros Neto, Synergism Study of Mixtures of Ionic and Nonionic Surfactants in Enhanced Oil Recovery Adsorption, Brazilian Journal of Petroleum and Gas, 2017, 11, 91-97.

34 J.-h. Xu, N.-y. Gao, Y. Deng, M.-h. Sui and Y.-l. Tang, Perchlorate removal by granular activated carbon coated with cetyltrimethyl ammonium chloride, Desalination, 2011, 275, 87-92.

35 R. Mahmudov, C. Chen and C.-P. Huang, Functionalized activated carbon for the adsorptive removal of perchlorate from water solutions, Front. Chem. Sci. Eng., 2015, 9, 194208.

36 W. A. Kitahara, and A. Wamanabe, Electrical phenomena at interfaces, Marcel Dekker Inc, New York, 1983.

37 Y. Yukselen-Aksoy and A. Kaya, A study of factors affecting on the zeta potential of kaolinite and quartz powder, Environ. Earth Sci., 2011, 62, 697-705.

38 D. H. Everett, Basic Principles of Colloid Science, The Royal Society of Chemistry, 1988.

39 Y. Wang, M. I. Tejedor-Tejedor, W. Tan and M. A. Anderson, Influence of Solution Chemistry on the Dielectric Properties of $\mathrm{TiO}_{2}$ Thin-Film Porous Electrodes, J. Phys. Chem. C, 2016, 120, 21543-21551.

40 B. Ersoy and M. S. Çelik, Electrokinetic properties of clinoptilolite with mono-and multivalent electrolytes, Microporous Mesoporous Mater., 2002, 55, 305-312.

41 J. A. Menéndez, M. J. Illán-Gómez, C. A. L. y León and L. R. Radovic, On the difference between the isoelectric point and the point of zero charge of carbons, Carbon, 1995, 33, 1655-1657.

$42 \mathrm{H}$. Boehm, Some aspects of the surface chemistry of carbon blacks and other carbons, Carbon, 1994, 32, 759-769.

43 X. Song, H. Liu, L. Cheng and Y. Qu, Surface modification of coconut-based activated carbon by liquid-phase oxidation and its effects on lead ion adsorption, Desalination, 2010, 255, 78-83.

44 P. Somasundaran, S. Shrotri and L. Huang, Thermodynamics of adsorption of surfactants at solidliquid interface, Pure Appl. Chem., 1998, 70, 621-626.

45 Q. Xu, T. Vasudevan and P. Somasundaran, Adsorption of anionic-nonionic and cationic-nonionic surfactant mixtures on kaolinite, J. Colloid Interface Sci., 1991, 142, 528-534.

46 X. Zhang, X. Wang, J. Su, X. Wang, L. Jiang, H. Wu and C. $\mathrm{Wu}$, The effects of surfactant template concentration on the supercapacitive behaviors of hierarchically porous carbons, J. Power Sources, 2012, 199, 402-408.

47 J. H. Clint, Surfactant aggregation, Springer Science \& Business Media, 2012.

48 L. Guo, W. Y. Zhang, X. J. Zhao, L. R. Xiao, Z. Y. Cai, R. Pu and X. Q. Xu, Enhancing dispersion of ultra-fine WC powders in aqueous media, Colloids Surf., A, 2019, 567, 6368.

49 P. Suchomel, L. Kvitek, R. Prucek, A. Panacek, A. Halder, S. Vajda and R. Zboril, Simple size-controlled synthesis of $\mathrm{Au}$ nanoparticles and their size-dependent catalytic activity, Sci. Rep., 2018, 8, 4589.

50 J. Smitham and D. Napper, Steric stabilization in worse than $\theta$-solvents, Colloid Polym. Sci., 1979, 257, 748-756.

51 T. F. Tadros, Prevention of formation of dilatant sediments in suspension concentrates, Colloids Surf., 1986, 18, 427438.

52 H. Lee, R. Pober and P. Calvert, Dispersion of powders in solutions of a block copolymer, J. Colloid Interface Sci., 1986, 110, 144-148.

53 D. Napper, The role of polymers in the stabilization of disperse systems, in Chemistry and Technology of WaterSoluble Polymers, Springer, 1983, pp. 233-248.

54 B. Fang, Y. Z. Wei, K. Suzuki and M. Kumagai, Surface modification of carbonaceous materials for EDLCs application, Electrochim. Acta, 2005, 50, 3616-3621.

55 L. H. Tamborini, M. E. Casco, M. P. Militello, J. SilvestreAlbero, C. A. Barbero and D. F. Acevedo, Successful application of a commercial cationic surfactant mixture (benzalkonium chloride) as porosity stabilizer in porous carbons fabrication, Colloids Surf., A, 2016, 509, 449-456. 
56 A. Muto, Y. Sasada, T. Bhaskar and Y. Sakata, Improvement of Specific Capacitance with Addition of Surfactants to an Aqueous Electrolyte, Electrochemistry, 2007, 75, 598-600.

57 C. Rulison, Application Report, 2007.

58 S. Gangula, S.-Y. Suen and E. D. Conte, Analytical applications of admicelle and hemimicelle solid phase extraction of organic analytes, Microchem. J., 2010, 95, 2-4.
59 T. Behrends and R. Herrmann, Adsolubilization of anthracene on surfactant covered silica in dependence on $\mathrm{pH}$ : indications for different adsolubilization in admicelles and hemimicelles, Colloids Surf., A, 2000, 162, 15-23.

$60 \mathrm{M}$. Hiraide and A. Ishikawa, Alumina and admicellar sorbents for the separation of copper (II) ions and humic complexes in water, Anal. Sci., 2002, 18, 199-201. 